Article

\title{
Exploring Land Use and Land Cover Effects on Air Quality in Central Alabama Using GIS and Remote Sensing
}

\author{
Stephen D. Superczynski ${ }^{1, *}$ and Sundar A. Christopher ${ }^{2}$ \\ 1 Earth System Science Center, The University of Alabama in Huntsville, Huntsville, AL 35899, \\ USA \\ 2 Department of Atmospheric Science, The University of Alabama in Huntsville, Huntsville, \\ AL 35899, USA; E-Mail: sundar@nsstc.uah.edu \\ * Author to whom correspondence should be addressed; E-Mail: super@nsstc.uah.edu; \\ Tel.: +1-256-961-7030.
}

Received: 30 September 2011; in revised form: 17 November 2011 / Accepted: 17 November 2011 / Published: 25 November 2011

\begin{abstract}
Air pollution has been a major topic of debate in highly developed areas over the last quarter century and therefore mitigation of poor air quality for health and environmental reasons has been a primary focus for local governments. Particulate matter, especially finer particles $\left(\mathrm{PM}_{2.5}\right)$, is detrimental to human health, and urban expansion is thought to be a contributing factor to enhanced levels of $\mathrm{PM}_{2.5}$. However, there is limited research on the connection between land use and land cover change (LULC) and $\mathrm{PM}_{2.5}$ emissions. Using high resolution LANDSAT imagery from the past 12 years along with ground observations of $\mathrm{PM}_{2.5}$ mass concentrations in the Birmingham, $\mathrm{AL}$ region, we explore the links between the $\mathrm{PM}_{2.5}$ mass concentrations and LULC trends. Utilization of GIS allowed us to seamlessly analyze county-based patterns of LULC change and $\mathrm{PM}_{2.5}$ concentrations and display them in an easy to interpret manner. We found a moderate-to-strong correlation between $\mathrm{PM}_{2.5}$ observations and the urban area surrounding monitoring sites in 1998 and 2010. We also discuss factors such as local climate and topography and EPA imposed standards that can confound these comparisons. Finally, we determine the next steps that are required to fully quantify the cause and effect between LULC and air quality.
\end{abstract}

Keywords: satellite remote sensing; particulate matter; air quality; environmental policy 


\section{Introduction}

Poor air quality is one of the greatest environmental hazards facing many urban areas around the globe. With over half of the world's population living in urban regions, the effects of air quality on public health must be addressed [1]. As cities grow in population and size, there is an increase in energy consumption, industrial emissions, and vehicular traffic, all of which can have an adverse effect on air quality [2]. The Kahyaoglu-Koracin study focused mainly on mobile emissions in the Southern CA region and found a near-linear relationship between modeled population and emission increases. For every half-million increase in the population, emissions have grown by approximately $15 \%$. One of the most prominent and regulated air pollutants is particulate matter (PM). PM, or aerosols, is a complex mixture of very small solid particles or liquid droplets suspended in the air. These particulates can be a result of anthropogenic processes such as fossil fuel combustion or biomass burning [3,4], or can come from natural sources such as sea salt and dust, although some dust emissions can be deemed anthropogenic if they originate from such processes as mining or farming [5].

$\mathrm{PM}_{2.5}$ is the designation for particulates that are less than $2.5 \mu \mathrm{m}$ in aerodynamic diameter, making it small enough to be inhaled. Over the past century there have been multiple studies linking severe pollution events to increased occurrences of illness and even death [6-10]. In recent decades the focus has shifted more toward the effects of long-term exposure to PM at moderate levels typically seen in inhabited regions [11,12]. According to the World Health Organization (WHO), regular exposure to $\mathrm{PM}_{2.5}$ has been linked to an increased risk of cardiovascular or respiratory disease, along with lung cancer. $\mathrm{PM}_{2.5}$ can also cause a myriad of short term health issues such as respiratory infections, irritation of the eyes and nose, and headaches [13]. In addition to health concerns, suspended particulates also reduce visibility and contain harmful compounds which can cause environmental damage via dry or wet deposition.

The type of PM and its concentration depend on location, but there is a larger variability in and around highly developed urban areas [14]. The types of land use and land cover (LULC) practices seen in these larger cities can influence the amount of PM by replacing natural land cover with manmade sources of pollution. The conversion of forest, grasslands and farmland to residential housing, industrial complexes and large commercial centers often lead to an increase in emissions. The extreme case of this type of expansion is urban sprawl, which is characterized by decentralized patterns of low density development, often in an automobile-oriented fashion.

Many primary sources of air pollution have been discussed, but there are other secondary sources of particle pollution that are a result of chemical reactions that take place in the lower atmosphere. The formation of aerosols from emitted gases such as $\mathrm{SO}_{2}$ and $\mathrm{NO}_{2}$ and Ammonia also contribute to PM. Therefore when trying assess air pollution in a particular region the proximity to sources such as industrial and power plants along with vehicular traffic, all of which are a result of urbanization, needs be accounted for. Moreover air pollution can be transported from one region to another further complicating the problem. Local topography and prevailing meteorological conditions also can have a large effect on air pollution. As will be shown in the discussion that follows, these are important factors. Therefore, when assessing air pollution in a particular location, care must be taken to unravel cause-effect relationships 
In this study, we assess these relationships in and around the Birmingham, AL region. The intent is to fully understand those influences that would be vital when attempting to quantify the effect each can have on local $\mathrm{PM}_{2.5}$ mass concentrations. The effects of LULC on $\mathrm{PM}_{2.5}$ concentrations are not fully understood and most studies have focused on point sources and speciation. Therefore in this study we examine land use in proximity to air quality monitors and study the relationships between urban area and $\mathrm{PM}_{2.5}$ mass concentrations. Examining the amount and type of land use change that has taken place in a particular area along with the $\mathrm{PM}_{2.5}$ trends to determine their correlation is the most straightforward way of finding a possible link between the two. However, as mentioned previously there could be underlying factors that can complicate the analysis such as regional climate and terrain, which can affect both the transport of aerosols and even the emissions themselves. Changes to air quality regulations also can obscure the relationship by having an effect on the amount of allowed emissions put forth by environmental agencies. This type of analysis is complicated by the fact that limited data is available outside of major metropolitan areas, and the coverage of the Automated Surface Observation System (ASOS) weather stations is also somewhat limited. Therefore, trying to relate these variables to widespread LULC maps obtained via remote sensing is often challenging.

Several studies have been carried out in various regions that show LULC changes can be detected and quantified using satellite remote sensing and image processing techniques [15-18]. However, there have been a limited number of studies that attempt to relate changes to PM concentrations. A study by Weng et al. [19] looked at the relationship between levels of $\mathrm{SO}_{2}, \mathrm{NO}_{\mathrm{x}}$, and dust and the distance from roads and two pollution centers in Guangzhou City in South China. They used GIS to find the concentration of these pollutants in ten sequential buffers around the roads and pollution centers and correlate that to urban density. They found that $\mathrm{SO}_{2}$ levels were significantly correlated to the regions around the pollution centers but not the roadways, and the vice versa for $\mathrm{NO}_{\mathrm{x}}$. Dust was moderately correlated to the amount of urban land in all three scenarios. This study did discuss amounts of total suspended particulates (TSP); however, GIS and correlation analysis was not done due to a lack of data coverage.

In this study we use a similar general method as the one used in the Weng et al. study. In this case, however, the amount of urban land will be compared to $\mathrm{PM}_{2.5}$ data on a regional scale, and the analysis will be county-based and centered on $\mathrm{PM}_{2.5}$ monitoring stations. The goal of this paper is to explore the major factors that affect aerosol levels in the central Alabama region and determine which are the most influential on the recent $\mathrm{PM}_{2.5}$ record. In addition, we include the use of GIS technology and demonstrate its effectiveness in this area of research where much of the data is based on county boundaries. Having the ability to convey results in easily understood maps make it the optimal tool for environmental studies with policy implications.

\section{Study Area and Data}

Birmingham, AL is the largest city in Alabama, located in the central region of the state within Jefferson County. Birmingham has a long record of air pollution problems due to its history of steel production and importance as an industrial center in the Southeast. Severe air pollution events in the early 1970s led to some of the first implementations of the Federal Clean Air Act [20]. While air quality as a whole has improved since then, the Birmingham MSA continues to rank inside the top 10 
for the worst particle pollution in the nation [21]. Jefferson County and two neighboring counties, Shelby and Walker (Figure 1), have been in non-attainment of the EPA standards for air quality. A large part of this is due to three large coal-fired power plants that operate within those counties. These power plants and their expansion in recent years are necessitated by the growing population in the region. The Birmingham area has undergone significant growth in the last half century, particularly in its suburbs. In the twenty year period from 1970 to 1990 the city grew by 174.2 square miles, ranking it 27th in the nation in urban sprawl [22]. Due to its past problems in curtailing air pollution Birmingham also boasts a fairly extensive PM monitoring system. This coupled with its growth make it a logical choice for an initial case study.

Figure 1. Overview of the nine-county study area along with interstate highways and urban areas $(\tan )$. Particulate matter (PM) monitoring stations used in this study are shown in red and three major power plants in black circles.

\section{Study Area}
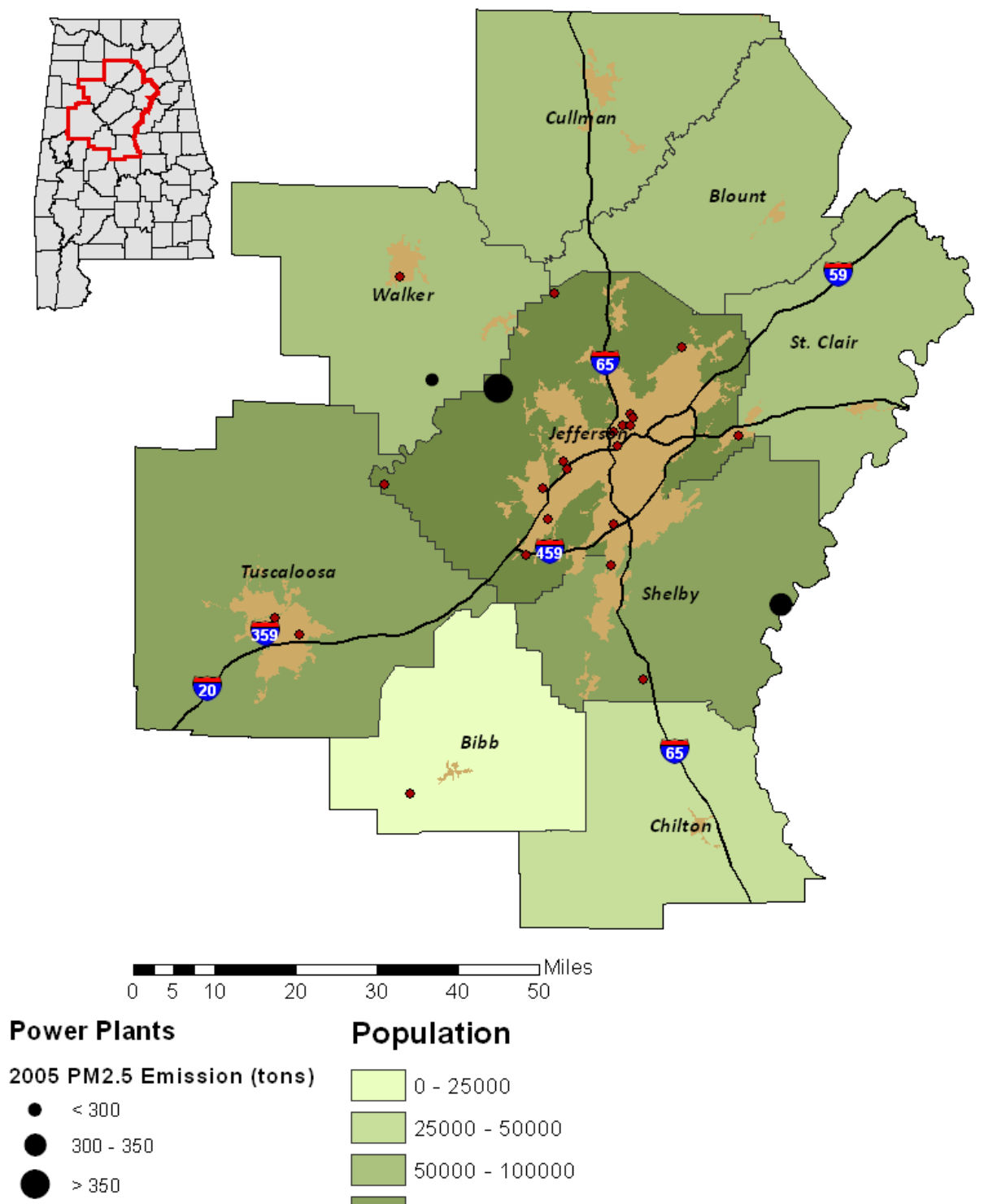

\section{Population}

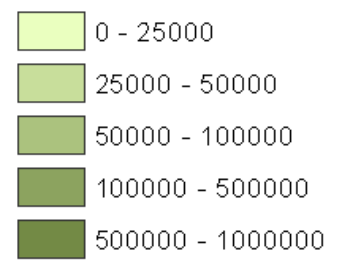


The nine-county study area shown in Figure 1 is located in central Alabama. It covers approximately $19,350 \mathrm{~km}^{2}$ and contains some large cities and sizable towns. The area has a wide variety of land cover classes including various levels of urban development, industries, agriculture, forested lands, mining, logging and numerous bodies of water. Since this study focuses on the amount of urban use versus non-developed land, the classes have been aggregated during post-classification into four general land use categories: urban, rural, forest and water.

PM concentration is measured at over 1,200 ground monitors throughout the US, and these measurements are used to determine whether counties are in attainment of EPA standards required by the Clean Air Act [23]. These standards, termed the National Ambient Air Quality Standards (NAAQS), have been revised over the years to further restrict pollutants. Since $\mathrm{PM}_{2.5}$ was not widely measured until the late 90's restrictions on emissions were not developed until 1997. These $\mathrm{PM}_{2.5}$ standards were tightened in 2005 and currently the daily maximum for $\mathrm{PM}_{2.5}$ is $35 \mu \mathrm{g} \mathrm{m}^{-3}$ and the annual standard is $15 \mu \mathrm{g} \mathrm{m}^{-3}$. $\mathrm{PM}_{2.5}$ data is measured at various sampling frequencies; however, most are sampled daily or hourly. These observations were obtained from the EPA's Air Quality System (AQS) and then aggregated into yearly averages of mass concentration.

To estimate the LULC in the Birmingham area, eight predominately cloud-free LANDSAT 5 TM scenes in total were collected for 1998 and 2010. The images are in GeoTIFF format and are Level 1 Terrain (L1T) products which have undergone radiometric, geometric and terrain correction. The images have also been rectified to the Universal Transverse Mercator (UTM) projection and WGS84 Datum employing ground control points using a cubic convolution method of resampling. The images were then processed to create mosaic composites of the study area and perform supervised classification in order to create the LULC maps for each year. The classification method utilized for this study was a maximum likelihood classification followed by a set of post-classification routines including combining of classes, and sieving/clumping (ITT, 2009) to reduce sporadic pixels and combine similar adjacent pixels.

The classification process begins with selecting representative samples of each class present in the image. Previous knowledge along with aerial imagery was used to determine and select these training samples. For this study, the goal was to determine the expansion of the developed urban areas at the expense of surrounding rural and forested land using Level I Anderson classification [24]. However, in order to properly classify the images some classes needed to be split into subclasses and then combined into Level I in post-classification processing. The urban class was broken down into two subclasses: one representing a highly developed dense urban landscape and the other consisting of low density areas which were mainly residential subdivisions or large singular houses or similar structures. Next the forested regions were subdivided to classify dense healthy forested regions and areas where previous logging or clearing had left behind scrub/shrub type vegetation. Finally, the agricultural areas were broken down into three subclasses: crops and lush pasture; cultivated or exposed earth; and another class for recently harvested or unhealthy/dormant vegetation.

\section{Results and Observations}

Since 1998, the area surrounding Birmingham, AL has continued its trend of growth and land cover change as can be seen in Figure 2. Over this time within the study area, the percent of overall 
urbanized area increased by nearly $4 \%$ with the amount of urban land growing more in some counties than others. Table 1 shows the results from the LULC analysis by county and the total for the entire nine-county region for 1998 and 2010. In 1998, Jefferson County was by far the most urbanized county in the region with almost $18 \%$ of its area being characterized as developed land while many of the remaining counties average around 5\%. The statistics for 2010 show a very different picture, however, as five of the nine counties saw their urban land grow by at least $40 \%$.

Figure 2. The progression of urbanized land around the city of Birmingham since 1998. Expansion has been greater in southern sections of the city and closely follows major transportation routes in the region.

\section{Urban Extent}

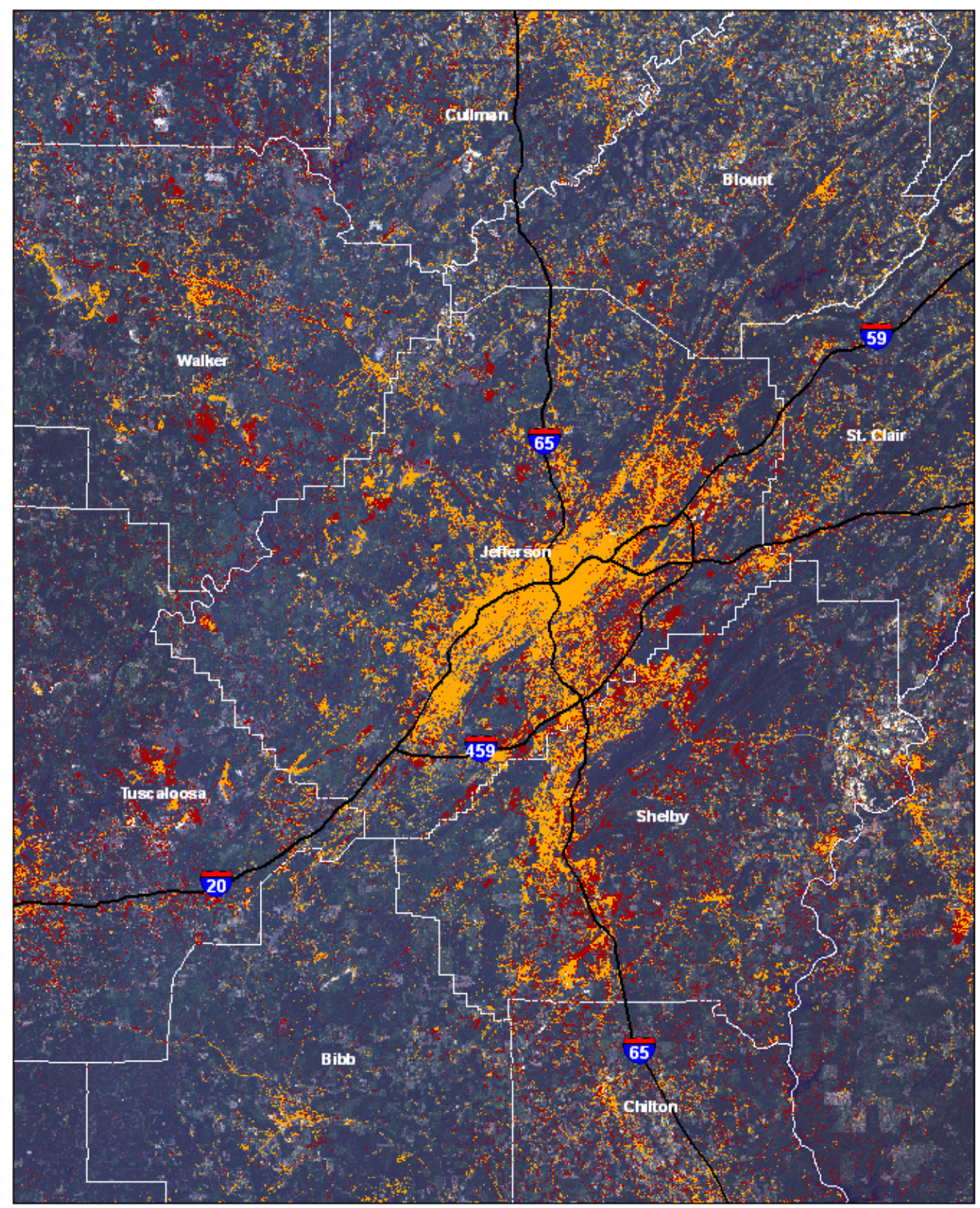


Table 1. Classification statistics for the nine counties in the study region for 1998 and 2010.

\begin{tabular}{|c|c|c|c|c|c|c|c|c|c|c|c|c|c|}
\hline \multirow[b]{3}{*}{ County } & \multirow[b]{3}{*}{ Total Area } & \multicolumn{6}{|c|}{1998} & \multicolumn{6}{|c|}{2010} \\
\hline & & \multicolumn{2}{|c|}{ Urban } & \multicolumn{2}{|c|}{ Rural } & \multicolumn{2}{|c|}{ Water } & \multicolumn{2}{|c|}{ Urban } & \multicolumn{2}{|c|}{ Rural } & \multicolumn{2}{|c|}{ Water } \\
\hline & & $\left(\mathrm{km}^{2}\right)$ & $\%$ & $\left(\mathrm{~km}^{2}\right)$ & $\%$ & $\left(\mathrm{~km}^{2}\right)$ & $\%$ & $\left(\mathrm{~km}^{2}\right)$ & $\%$ & $\left(\mathrm{~km}^{2}\right)$ & $\%$ & $\left(\mathrm{~km}^{2}\right)$ & $\%$ \\
\hline Bibb & $1,620.5$ & 33 & 2.0 & $1,583.9$ & 97.7 & 3.6 & 0.2 & 47.2 & 2.9 & $1,569.8$ & 96.9 & 3.4 & 0.2 \\
\hline Blount & $1,683.9$ & 96.4 & 5.7 & $1,578.1$ & 93.7 & 9.3 & 0.6 & 97.3 & 5.8 & $1,577.1$ & 93.7 & 9.4 & 0.6 \\
\hline Chilton & $1,813.7$ & 73.3 & 4.0 & $1,725.2$ & 95.1 & 15.2 & 0.8 & 159.1 & 8.8 & $1,638.1$ & 90.3 & 16.4 & 0.9 \\
\hline Cullman & $1,953.9$ & 171.3 & 8.8 & $1,733.1$ & 88.7 & 34.7 & 1.8 & 173 & 8.9 & $1,750.4$ & 89.6 & 30.6 & 1.6 \\
\hline Jefferson & $2,908.4$ & 517.3 & 17.8 & $2,370.6$ & 81.5 & 20.5 & 0.7 & 665.1 & 22.9 & $2,219.8$ & 76.3 & 23.3 & 0.8 \\
\hline Shelby & $2,095.0$ & 172.1 & 8.2 & $1,889.9$ & 90.2 & 33.1 & 1.6 & 330.1 & 15.8 & $1,730.4$ & 82.6 & 34.4 & 1.6 \\
\hline St. Clair & $1,691.7$ & 102.2 & 6.0 & $1,536.6$ & 90.8 & 48.9 & 2.9 & 115.2 & 6.8 & $1,529.6$ & 90.4 & 46.8 & 2.8 \\
\hline Tuscaloosa & $3,497.1$ & 108.7 & 3.1 & $3,332.4$ & 95.3 & 56 & 1.6 & 317.7 & 9.1 & $3,124.6$ & 89.3 & 54.8 & 1.6 \\
\hline Walker & $2,083.8$ & 92.9 & 4.5 & $1,972.8$ & 94.7 & 18.1 & 0.9 & 181.4 & 8.7 & $1,883.9$ & 90.4 & 18.5 & 0.9 \\
\hline Total & $19,348.0$ & $1,367.2$ & 7.1 & $17,722.6$ & 91.6 & 239.4 & 1.2 & $2,086.1$ & 10.8 & $17,023.7$ & 88.0 & 237.6 & 1.2 \\
\hline
\end{tabular}

While Jefferson County is still the most developed county in the study region with nearly a quarter of it classified as urban area, some neighboring counties such as Shelby and Walker almost doubled their urbanized area. This is due to the fact that the expansion of the city of Birmingham and its suburbs spilled over into these adjacent counties over time. The percent change per county for each class over the entire 12-year period is given in Table 2.

Table 2. Percent change of land use categories from 1998 to 2010 based on county.

\begin{tabular}{cccc}
\hline County & Urban & Rural & Water \\
\hline Bibb & 43.03 & -0.89 & -5.56 \\
Blount & 0.93 & -0.06 & 1.08 \\
Chilton & 117.05 & -5.05 & 7.89 \\
Cullman & 0.99 & 1.00 & -11.82 \\
Jefferson & 28.57 & -6.36 & 13.66 \\
Shelby & 91.81 & -8.44 & 3.93 \\
St. Clair & 12.72 & -0.46 & -4.29 \\
Tuscaloosa & 192.27 & -6.24 & -2.14 \\
Walker & 95.26 & -4.51 & 2.21 \\
All Counties & $\mathbf{5 2 . 5 8}$ & -3.94 & -0.75 \\
\hline
\end{tabular}

As stated previously, urban sprawl is largely a transportation-oriented phenomenon. This is much of the reason for the growth seen on the south and southeastern sides of the city of Birmingham (Shelby and St. Clair counties). In the mid-80s, the I-459 bypass was completed, which improved major highway access to many of the southern suburbs of Jefferson County. Over time these neighborhoods grew and became more popular leading to accelerated expansion. Areas north and west of the city did not see this level of growth since they lacked direct interstate access, plus the fact that many of the industrial centers were located here likely making it less favorable for residential development. However, with a new interstate connecting Birmingham to Memphis, TN, and discussions of eventually expanding I-459 into a loop around the city, this could foster the same type of growth in the northern counties that was experienced south of Birmingham in the later parts of the 20th century. 
To further demonstrate the conversion of land use to a more highly developed state, population statistics have also been compiled starting with the 2000 census up until the most recent 2010 census. Numbers show that population increases coincide reasonably well with the amount of urban land per county over the study period. Shelby and St. Clair counties have seen their populations increase by $36 \%$ and $28 \%$, respectively, over the past 10 years as the city of Birmingham has expanded into these counties. However, there are a few counties which exhibit population increases that do not match up with the amount of change in urban land cover. Tuscaloosa and Chilton Counties saw major increases in the amount of urban area while their population increases were rather modest $(\sim 10 \%)$. It is possible that the urbanization is centered around commercial or industrial land uses rather than residential. Major interstates run through these counties and are likely a large part of this expansion, along with the presence of The University of Alabama in Tuscaloosa. Walker County displays the same phenomenon, except its population actually decreased since 2000. Its urban expansion is largely due to large mining operations being established or expanded over the last 12 years.

While urban expansion continued at a moderate pace during the last 15 years, the ambient air quality trends have been less stable within the study region. In $1999, \mathrm{PM}_{2.5}$ became the new primary measurement of particle pollution due to growing evidence in the 1990s that showed negative health effects to the general population even when PM levels were below the then-current NAAQS and that the possibility of a subset of finer particles were the primary cause [11,25,26]. Prior to 1998, there were limited amount of locations in the country that measured $\mathrm{PM}_{2.5}$. Figure 3 shows the annual mass concentrations for $\mathrm{PM}_{2.5}$ for all sites within the study region. $\mathrm{PM}_{2.5}$ pollution dropped sharply in the region following its inclusion in the NAAQS, followed by an increase in $\mathrm{PM}_{2.5}$ from 2004 to 2007. Figure 4 shows the breakdown of $\mathrm{PM}_{2.5}$ emissions based on sector for the three counties previously in non-attainment of the NAAQS (Jefferson, Walker, and Shelby counties) where electricity generation and industrial processes account for a majority of the emissions in the region. Jefferson County is the county with the most $\mathrm{PM}_{2.5}$ emissions with a total output of over 16,300 tons in 2005.

Figure 3. $\mathrm{PM}_{2.5}$ trends since monitoring began in 1998 for all stations in the study region.

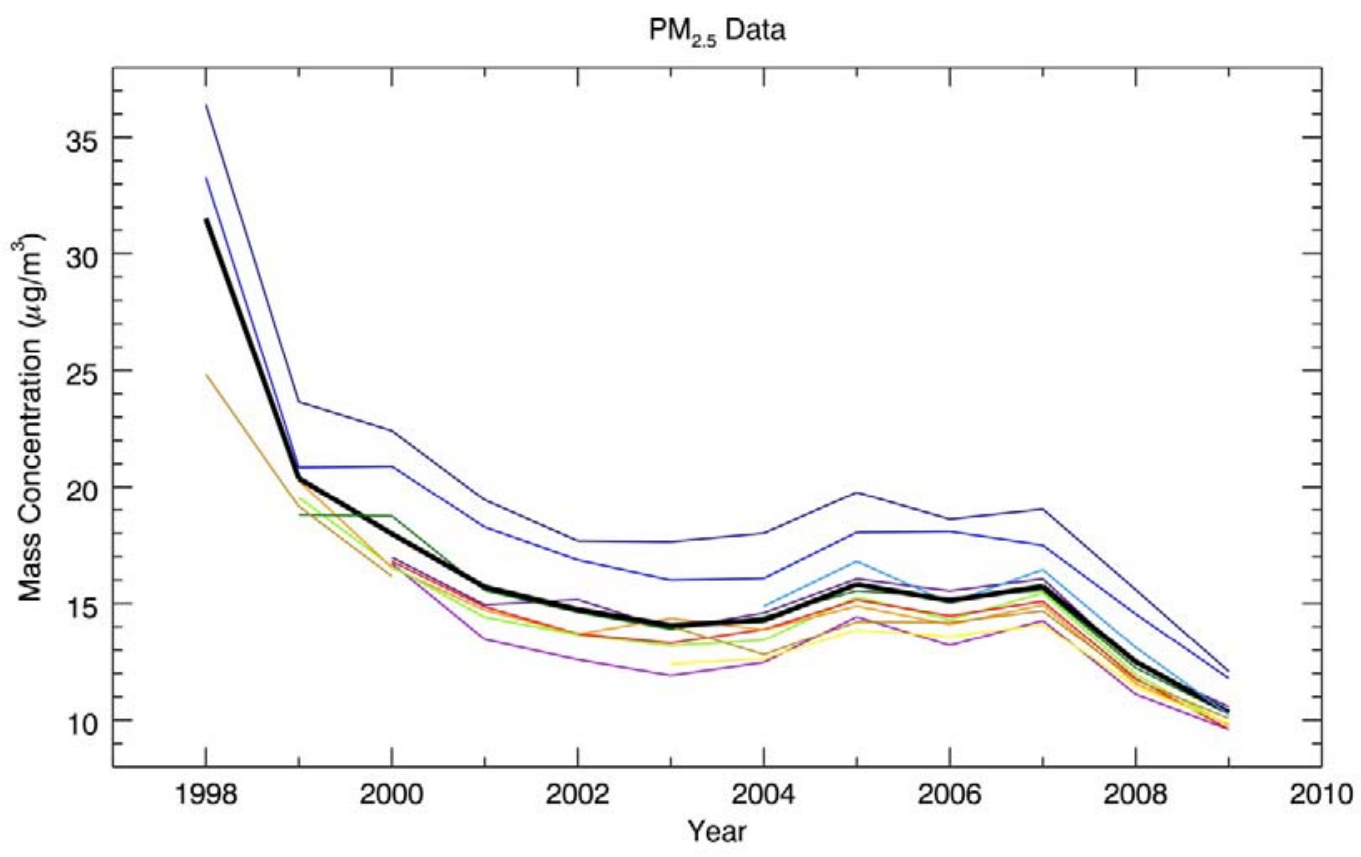


Figure 4. Breakdown of $\mathrm{PM}_{2.5}$ emissions by source sector for the three most polluted counties in Alabama.
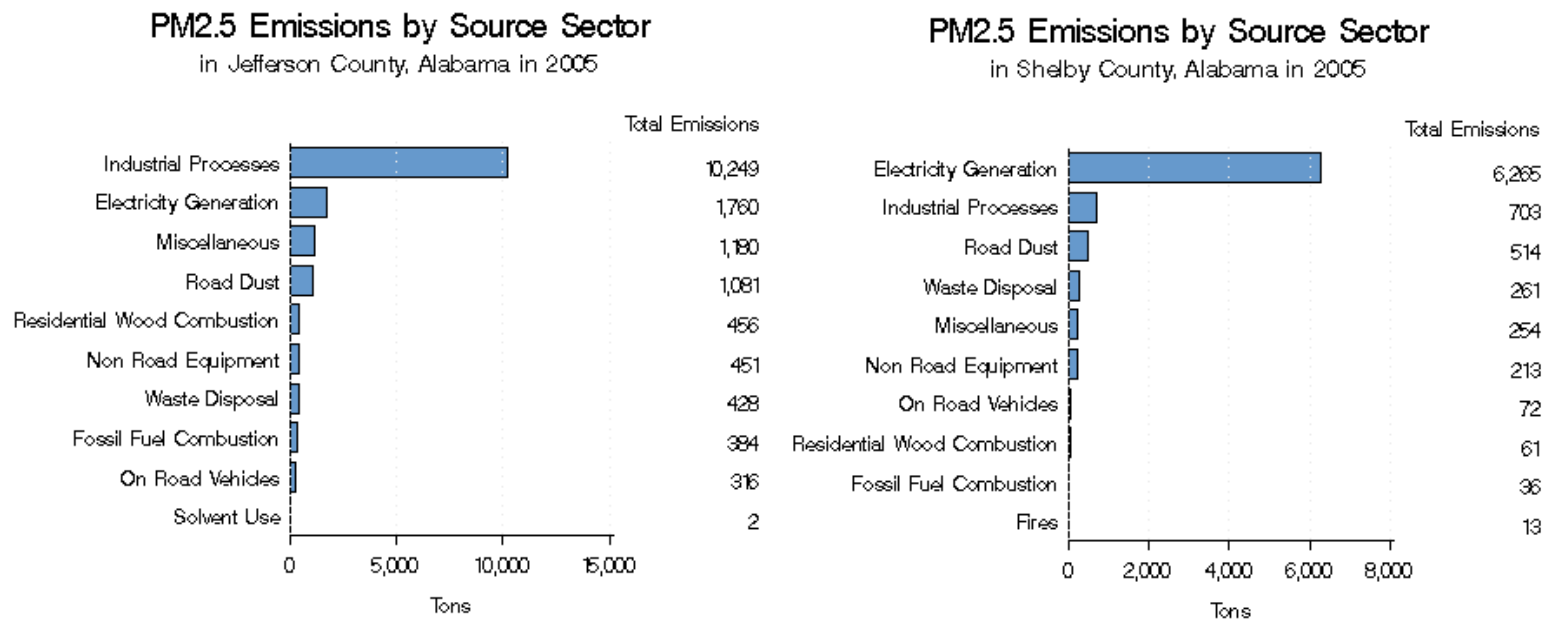

PM2.5 Emissions by Source Sector

in Walker County, Alabama in 2005

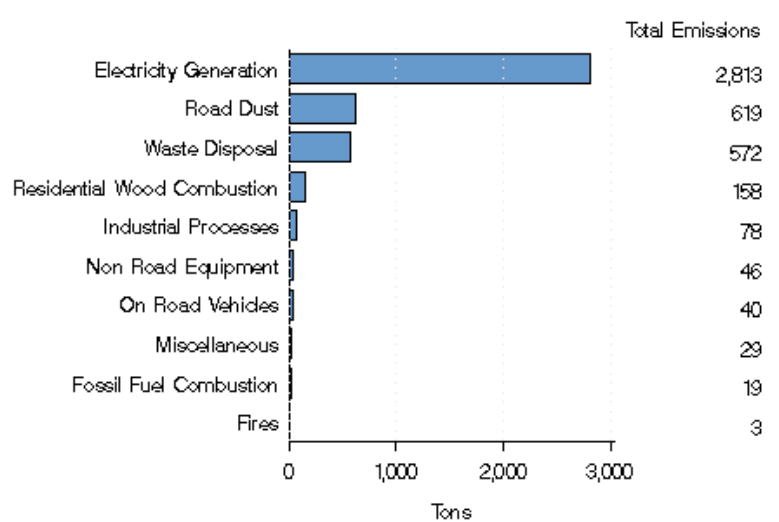

The main reason for this is the large number of industrial emission sources located in the city of Birmingham in relation to other areas, as seen in Figure 5. The high density of industries and their resulting particulate pollution within the urban areas shaded in red cause $\mathrm{PM}_{2.5}$ levels to be much higher in the city as evidenced by interpolated mass concentrations. These contours were calculated using a Triangulated Irregular Network (TIN) model based on air pollution monitor observations in the region.

Table 3 lists the total non-mobile source emissions for each county in the study region for 2002, 2005, and 2008. This data is collected by the EPA every three years via the National Emission Inventory (NEI) database and shows that emissions were higher in most counties in 2005 than 2002 or 2008. Jefferson County had large reductions in its $\mathrm{PM}_{2.5}$ emissions between 2005 and 2008 while emissions in Shelby County increased significantly in that time span. Part of this is likely due to the data collection process itself as the physical address of large emitters near county borders were consolidated during these years. These emission statistics match up well with the $\mathrm{PM}_{2.5}$ mass concentrations shown in Figure 3 with the higher emissions in 2005 coinciding with a peak in annual ground level $\mathrm{PM}_{2.5}$. 
Figure 5. Map centered on Jefferson County shows emission sources of $\mathrm{PM}_{2.5}$ (black circles), $\mathrm{PM}_{2.5}$ monitoring sites (colored circles and grey labels) and resulting interpolated contours of $\mathrm{PM}_{2.5}$ mass concentration in graduated color scheme. Shaded relief background map shows the local topography and water features.

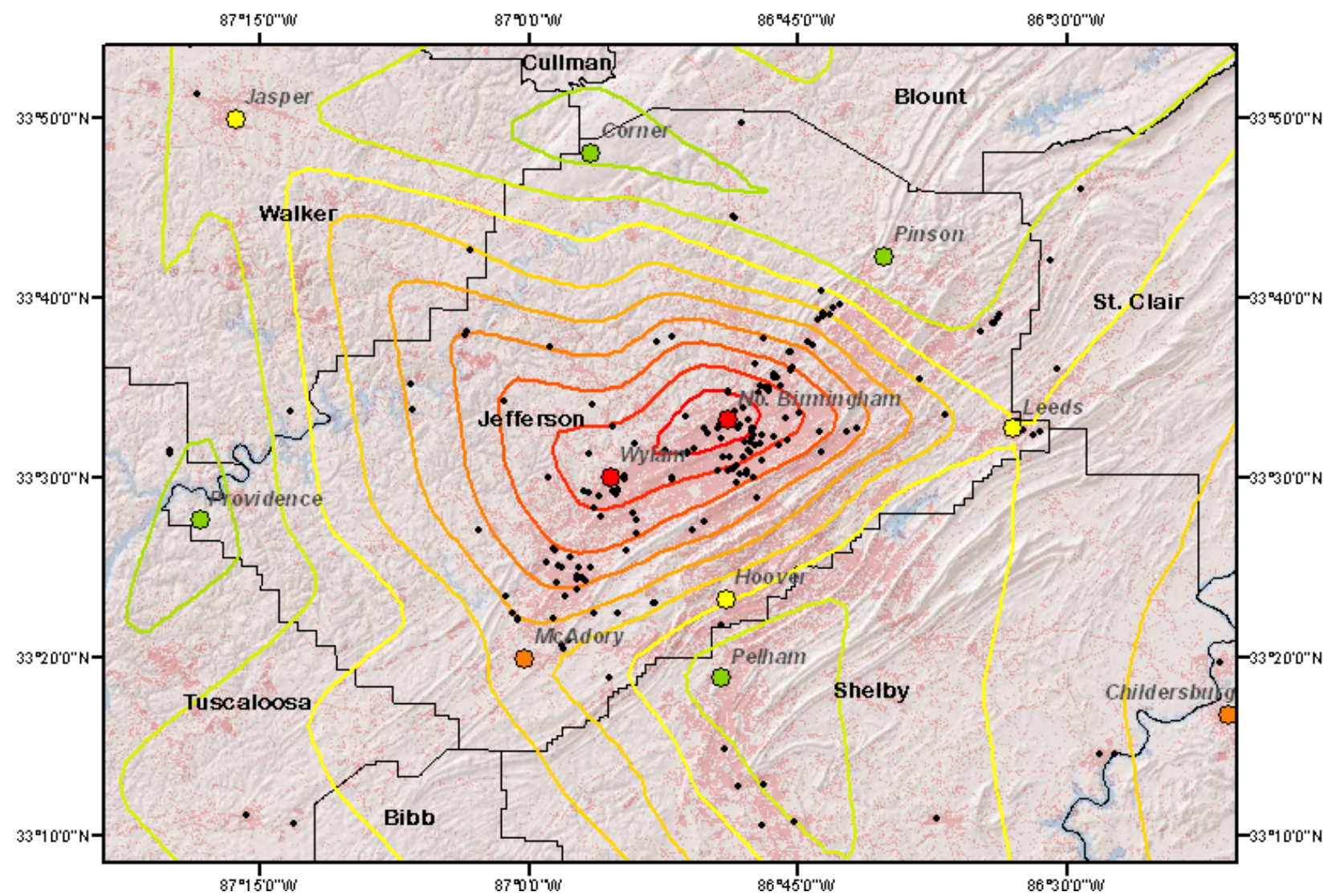

Table 3. Annual emissions from non-mobile sources for each county in the study region.

\begin{tabular}{lrrr}
\hline County & $\mathbf{2 0 0 2}$ & $\mathbf{2 0 0 5}$ & $\mathbf{2 0 0 8}$ \\
\hline Jefferson & 11,892 & 12,108 & 5,047 \\
Shelby & 1013 & 6,899 & 11,808 \\
Bibb & 27 & 23 & 23 \\
Walker & 3,176 & 2,887 & 1,926 \\
Tuscaloosa & 421 & 309 & 104 \\
St. Clair & 247 & 147 & 113 \\
Chilton & 155 & 64 & 70 \\
Blount & 0 & 0 & 0 \\
Cullman & 4 & 65 & 39 \\
\hline
\end{tabular}

The PM history in the Birmingham region shows periods of gradual increases of mass concentration and times where significant reductions in the amount of PM occurred. Gradual increases would be expected as urbanization and industrial output continue, but the sharp drops and interspersed short term spikes cannot be explained by land use alone. In reality, there are multiple factors contributing to this trend. One of the most influential may be the NAAQS themselves since their implementation would force local governments to enact guidelines on how to reduce emissions to avoid counties being considered in non-attainment of the standards. Following the implementation of $\mathrm{PM}_{2.5}$ standards in 
1997 and their revision in 2006, concentrations dropped significantly as can be seen in Figure 3. Therefore, it is probable that these reductions are a result of the US EPA standards and not directly related to urbanization.

The second major factor to take into account is that of local meteorology and terrain. The climate in the central Alabama region during the summer can be generally described as hot, humid, and often stagnant due to the Bermuda High that can occur during these months. This results in the formation of inversions, some lasting days, which trap harmful particles in the planetary boundary layer (PBL). Inversions are typically caused by diurnal variations in temperature or advection of a stable air mass into the region and are broken down by the vertical mixing of winds. Working in tandem with the inversion itself, the surrounding mountain ridges of Birmingham do not allow for the dispersion of these particulates. Figure 5 illustrates how much of the developed area and more importantly the industrial sources are located in the valley that encompasses much of the city of Birmingham.

Higher temperatures and humid air leads also leads to more energy being used to cool homes and workplaces. Therefore prolonged heat waves can increase power plant emissions as consumption rises. In addition wind patterns play a role in the transport of PM. For instance, in the summer months from 2000 to 2010 the average wind speed and direction was just over $1.3 \mathrm{~m} \mathrm{~s}^{-1}$ out of the SSW. The slow wind speeds coupled with their high variability $(\sigma=0.9)$ during this season means that sustained winds in the same direction are not common. This along with a SW to NE oriented ridges rising $150 \mathrm{~m}$ over the surrounding terrain means that wind transport during typical summer conditions is not easily achieved. Precipitation also has an effect on air quality because aerosols are a source of cloud condensation nuclei, which become entrained into storms and are removed by raindrops (wet deposition).

A prime example of how many of these factors can come together to influence air quality is evident in 2005 and 2007. During this time period temperatures were above normal, particularly in the summer months when air quality is typically at its worst. Also, a record breaking drought was taking place in the Southeast peaking in 2007 when the total rainfall in the city of Birmingham was 30 inches, making it the driest year on record in over a hundred years. Looking at both the $\mathrm{PM}_{2.5}$ records, we see that mass concentrations for these two years rose at nearly all monitoring sites in the region before falling again due to new restrictions on $\mathrm{PM}_{2.5}$ and a changeover to a cooler and wetter climate in 2008 and 2009.

While trends in air quality and land use over time are not similar due to other influences, there could be a strong relationship between urban land and $\mathrm{PM}_{2.5}$ at any given time. To examine this issue, a buffer analysis was completed using all the monitoring stations located in the nine-county study area that had a $\mathrm{PM}_{2.5}$ record stretching from 1998 to 2010 . Seven stations were used and a $10 \mathrm{~km}$ buffer was taken around each site and the amount of urban land was totaled (low and high density). The seven stations, which are shown in Figure 5, are North Birmingham, Wylam, Hoover, Pinson, Pelham, Jasper, and Childersburg. The urban land totals were compared to the annual average $\mathrm{PM}_{2.5}$, and correlation statistics were compiled for both 1998 and 2010. We found that the correlation (r) for 1998 is 0.67 and $r=0.63$ for 2010 , implying a strong correlation between the amount of urban land within the buffer zone and the average level of $\mathrm{PM}_{2.5}$ measure at the center of the buffer for both years. The correlation increases to $r=0.78$ and $r=0.76$ respectively if you exclude the Childersburg site, which is in a rural area but is also located 6 miles downwind from a large coal-fired power plant, which has 
likely skewed the $\mathrm{PM}_{2.5}$ numbers. Of course, this result is just a preliminary analysis that shows there is possible causality between LULC and $\mathrm{PM}_{2.5}$. We understand that the data used here is limited; however, it does show a need for further research and data collection in order to expand the correlation analysis to include more frequent LULC data which would allow us to increase the number of PM 2.5 monitors used.

After studying the $\mathrm{PM}_{2.5}$ trend over the last 12 years and comparing it to the increasing population and amount of urban land buildup we became aware that there are other variables that can obscure the real effect that urbanization can have on $\mathrm{PM}_{2.5}$ in a region. In order to find a robust quantifiable relationship between the two, a statistical and mathematical analysis of all the major factors that can directly influence $\mathrm{PM}_{2.5}$ emissions or transport is needed. To be truly meaningful, this type of study would require datasets with similar spatial and temporal resolution/extent. Unfortunately, the $\mathrm{PM}_{2.5}$ monitoring network and Automatic Surface Observing System (ASOS) stations are limited outside of urban centers. Monitoring stations tend to be situated around sources of pollution and adjacent neighborhoods. This is helpful for tracking pollution levels for use in assuring compliance with national standards, but it does not allow us to gain an accurate regional perspective on $\mathrm{PM}_{2.5}$. Studies in recent years [27-30] have shown that a combination of ground $\mathrm{PM}_{2.5}$ measurements and satellite retrieved AOT can provide a better spatial assessment than ground observations alone at regional to global scales.

In 2009, Gupta and Christopher outlined a method for estimating ground level $\mathrm{PM}_{2.5}$ from the MODIS Level 2 Aerosol product using linear and multiple regression techniques [31]. Using MODIS AOD data along with ground measurements they determined a linear relationship between $\mathrm{PM}_{2.5}$ and AOD for each season in the Southeast based on location $\left(2^{\circ} \times 2^{\circ}\right.$ grid $)$. To show the potential value to future air quality studies, we constructed a simple map of estimated ground level $\mathrm{PM}_{2.5}$ using the results from their linear regression analysis. Figure 6 shows the estimated $\mathrm{PM}_{2.5}$ mass concentrations in the Southeast for the time period March 2007 through November 2007 (seasons with higher correlation between $\mathrm{AOD}$ and $\mathrm{PM}_{2.5}$ ). In this image the pollution from major cities is evident by their relatively higher levels of $\mathrm{PM}_{2.5}$ as shown by areas of yellow and red. Also clearly visible is the impact of the large fires that took place in southeastern Georgia in the spring of 2007, which is responsible for much of the elevated $\mathrm{PM}_{2.5}$ amounts throughout much of Georgia along with eastern Alabama and southeastern Tennessee. Given the location of the $\mathrm{PM}_{2.5}$ monitoring sites shown in Figure 6, we can see how satellite data can be useful in gauging particulate pollution in areas where ground monitors are limited or non-existent. Satellite data helps give us a regional map of $\mathrm{PM}_{2.5}$ that is likely more accurate than interpolation of the observations from widely scattered ground monitors. The result is a more complete picture of $\mathrm{PM}_{2.5}$ allowing us to better relate LULC changes to $\mathrm{PM}_{2.5}$ levels over a larger area that would be difficult using surface observations alone.

Another possible enhancement to this study would be the use of higher quality datasets and those with a greater frequency of observation. The National Land Cover Dataset (NLCD) developed by the Multi-Resolution Land Characteristics Consortium (MRLC) is an example of this. The NLCD have been some of the most comprehensive and accurate land cover datasets created for the entire US [32,33]. These maps would provide a detailed look at the various land uses in a region and allow for better determination of the impacts certain land use changes can have on air quality. The release of the updated NLCD 2006 in early 2011 provides an important update to previous datasets $(1992,2001)$ to 
study LULC change over a period of nearly 15 years. The ability to expand the spatial and temporal coverage of the datasets used in this study such as those previously mentioned would greatly enhance the accuracy and usefulness of the results on a regional scale.

Figure 6. Estimated $\mathrm{PM}_{2.5}$ mass concentrations $\left(\mu \mathrm{g} \mathrm{m}^{-3}\right)$ for the Southeast in 2007 with points showing air quality monitoring sites and lines depicting major highways in the region.

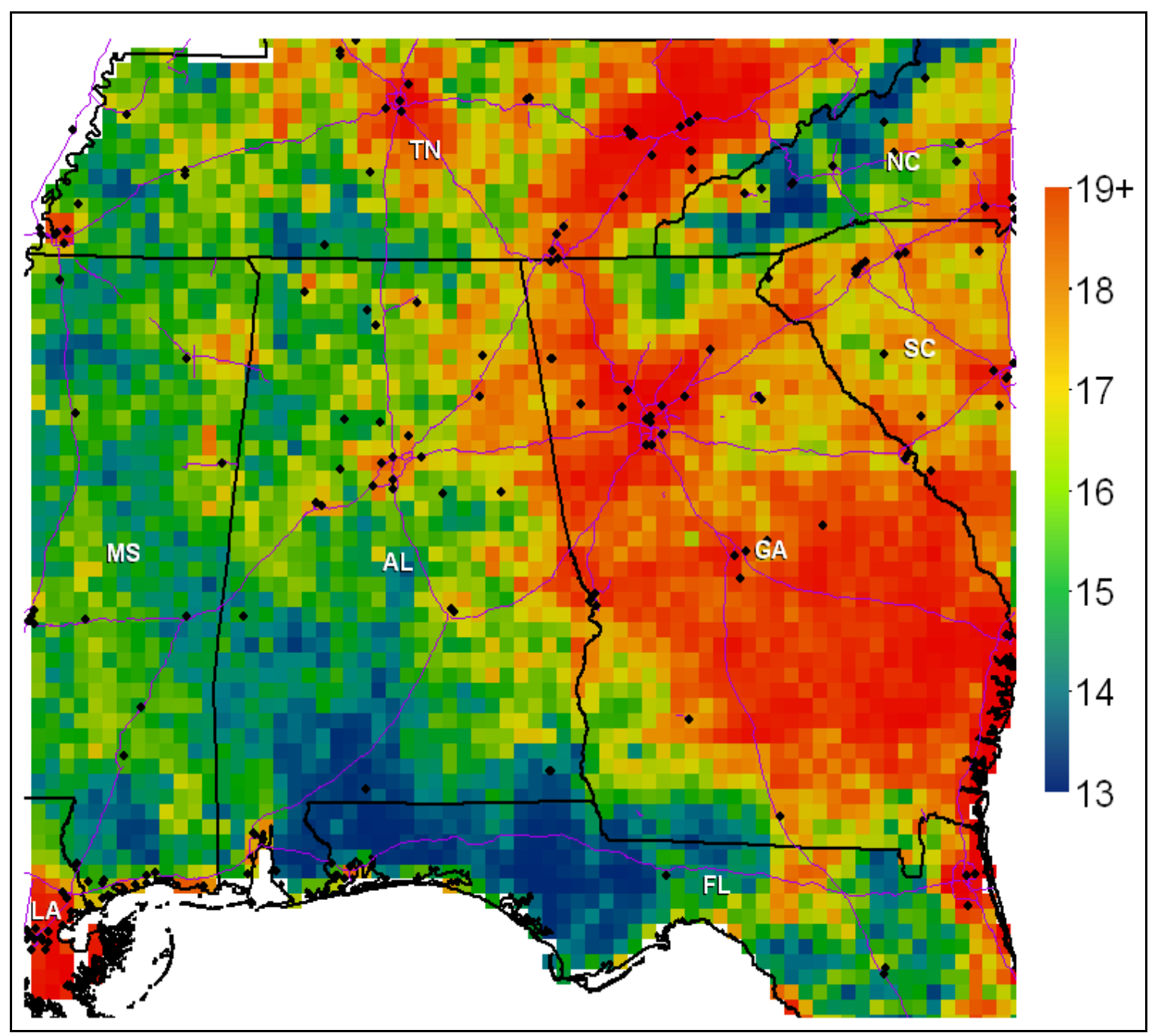

\section{Conclusions}

Finding a link between LULC changes and $\mathrm{PM}_{2.5}$ is a complex problem due to the outside influences on each variable. This paper has sought to outline some of the major issues that factor into a study of how regional land use changes can impact air quality, using Birmingham and the central Alabama region as an example. The observations gathered for this study showed instances where $\mathrm{PM}_{2.5}$ concentrations suddenly decreased or increased greatly from the preceding trend. While population and urbanization increased during this time, the $\mathrm{PM}_{2.5}$ pollution decreased overall. However, there are many outside factors, namely the implementation of NAAQS and local-to-regional climate and topography, which likely confound the relationship between the amount and type of LULC change and the PM record. While the $\mathrm{PM}_{2.5}$ trend did not appear to be positively correlated with trends in urban 
expansion over time, there is a strong correlation between amount of urbanization and average annual $\mathrm{PM}_{2.5}$ in a given area.

We have found that using the current network of $\mathrm{PM}_{2.5}$ ground monitors is limited in portraying regional air quality from a spatial standpoint. To help solve this problem, we demonstrated using a linear regression technique to produce regional maps of $\mathrm{PM}_{2.5}$. Using this framework and making adjustments to input datasets, such as weighting the results based on concurrent $\mathrm{PM}_{2.5}$ observations, should help improve the accuracy of such results. However, $\mathrm{PM}_{2.5}$ is only one piece of the puzzle, and improving and acquiring more LULC maps will be necessary to take full advantage of regional $\mathrm{PM}_{2.5}$ estimates. This could be achieved by either developing new datasets or through the use of future satellites, which will increase the quality of observations used in constructing LULC maps. By including datasets which improve both spatial and temporal coverage and resolution along with a multivariate statistical analysis, it may be possible uncover a significant link between LULC and particle pollution.

\section{Acknowledgments}

This research was supported by NOAA grants and funding from the Office of Vice President of Research at UAHuntsville.

\section{References}

1. UNFPA. State of World Population 2007: Unleashing the Potential of Urban Growth; 2007. Available online: http://www.unfpa.org/swp/2007/english/introduction.html (accessed on 10 November 2011).

2. Kahyaoglu-Koracin, J.; Basset, S.D.; Mouat, D.A.; Gertler, A.W. Application of a scenario-based modeling system to evaluate the air quality impacts of future growth. Atmos. Environ. 2009, 43, 1021-1028.

3. Coutant, B.W.; Engel-Cox, J.; Swinton, K.E. Compilation of Existing Studies on Source Appointment for PM 2.5 ; Technical Report Draft 1-05; US EPA: Triangle Park, NC, USA, 2003.

4. Husar, R.B.; Tratt, D.M.; Schichtel, B.A.; Ralke, S.R.; Li, F.; Jaffe, D.; Gasso, S.; Gill, T.; Laulainen, M.S.; Lu, F.; et al. Asian dust events of April 1998. J. Geophys. Res. 2001, 106, 18317-18330.

5. Zender, C.S.; Miller, R.L.; Tegen, I. Quantifying mineral dust mass budgets: Terminology, constraints, and current estimates. Eos Trans. AGU 2004, 85, 509-512.

6. Firket, J. Fog along the Meuse valley. Trans. Faraday Soc. 1936, 32, 1192-1196.

7. Logan, W.P.D. Mortality from fog in London, January 1956. Br. Med. J. 1956, 1, 722-725.

8. Ciocco, A.; Thompson, D.J. A follow-up of Donora ten years after: Methodology and findings. Am. J. Public Health 1961, 51, 155-164.

9. Ostro, B. A search for a threshold in the relationship of air pollution to mortality: A reanalysis of data on London winters. Environ. Health Persp. 1984, 58, 397-399.

10. Nemery, B.; Hoet, P.H.M.; Nemmar, A. The Meuse valley gog of 1930: An air pollution disaster. The Lancet 2001, 357, 704-708. 
11. Pope, C.A., III; Bates, D.V.; Raizenne, M.E. Health effects of particulate air pollution: Time for reassessment? Environ. Health Persp. 1995, 103, 472-480.

12. Samet, J.M.; Dominici, F.; Curriero, F.C.; Coursac, I.; Zeger, S.L. Particulate air pollution and mortality in 20 US Cities: 1987-1994. New Engl. J. Med. 2000, 343, 1742-1749.

13. Puett, R.C.; Hart, J.E.; Yanosky, J.D.; Paciorek, C.; Schwartz, J.; Suh, H.; Speizer, F.E.; Laden, F. Chronic fine and coarse particulate esposure, mortality, and coronary heart disease in the nurses' health study. Environ. Health Persp. 2009, 117, 1697-1701.

14. Paciorek, C.J.; Yanosky, J.D.; Puett, R.C.; Laden, F.; Suh, H.H. Practical Large-Scale Spatio-Temporal Modeling of Particulate Matter Concentrations; Harvard University Biostatistics Working Paper Series Paper 76; 2008.

15. Yang, X. Satellite monitoring of urban spatial growth in the Atlanta Metropolitan area. Photogramm. Eng. Remote Sensing 2002, 68, 725-734.

16. Yuan, F.; Sawaya, K.E.; Loeffelholz, B.C.; Bauer, M.E. Land cover classification and change analysis of the Twin Cities (Minnesota) Metropolitan area by multitemporal Landsat remote sensing. Remote Sens. Environ. 2005, 98, 317-328.

17. Gorsevski, P.V. Assessment of Land Use and Land cover Changes around Ohrid and Prespa Lakes using Landsat imagery. In Proceedings of BALWOIS 2008, Ohrid, Republic of Macedonia, 27-31 May 2008.

18. Deng, J.; Wang, K.; Jun, L.; Deng, Y. Urban land use change detection using multisensor satellite images. Pedosphere 2009, 19, 96-103.

19. Weng, Q.; Yang, S. Urban air pollution pattern, land use, and thermal landscape: An examination of the linkage using GIS. Environ. Monit. Assess. 2006, 117, 463-489.

20. Hardy, G.E., Jr.; Pate, P.; Robison, C.B.; Willis, W.T. First use of the Federal Clean Air Act's emergency authority. Am. J. Public Health 1974, 64, 72-76.

21. American Lung Association. State of the Air Report; American Lung Association: Washington, DC, USA, 2010. Available online: http:/www.lungusa.org/associations/states/california/advocacy/ fight-for-air-quality/sota-2010/state-of-the-air-report-2010.html (accessed on 10 November 2011).

22. Kolankiewicz, L.; Beck, R. Weighing Sprawl Factors in Large US Cities; NumbersUSA.com: Arlington, VA, USA, 2001.

23. Clean Air Act. US Code, Section 7409, Title 42, 2008.

24. Anderson, J.R.; Hardy, E.E.; Roach, J.T.; Witmer, R.E. A Land Use and Land Cover Classification System for Use with Remote Sensor Data; Geological Survey Professional Paper 964; US GPO: Washington, DC, USA, 1976.

25. Schwartz, J. Air pollution and daily mortality in Birmingham, Alabama. Am. J. Epidemiol. 1993, 137, 1136-1147.

26. Dockery, D.W.; Pope, C.A.; Xu, X.; Spengler, J.D.; Ware, J.H.; Fay, M.E.; Ferris, B.G.; Speizer, F.E. An association between air pollution and mortality in six US Cities. New Engl. J. Med. 1993, 329, 1753-1759.

27. Wang, J.; Christopher, S.A. Intercomparison between satellite-derived aerosol optical thickness and $\mathrm{PM}_{2.5}$ mass: Implications for air quality studies. Geophys. Res. Lett. 2003, 30, 2095. 
28. Liu, Y.; Park, R.J.; Jabob, D.J.; Li, Q.; Kilaru, V.; Sanat, J.A. Mapping annual mean ground-level $\mathrm{PM}_{2.5}$ concentrations using multiangle imaging spectroradiometer aerosol optical thickness over the contiguous United States. J. Geophys. Res. 2004, 109, D22206.

29. Gupta, P.; Christopher, S.A.; Wang, J.; Gehrig, R.; Lee, Y.C.; Kumar, N. Satellite remote sensing of Particulate Matter and air quality over global cities. Atmos. Environ. 2006, 40, 5880-5892.

30. Al-Hamdan, M.; Crosson, W.L.; Limaye, A.S.; Rickman, D.L.; Quattrochi, D.A.; Estes, M.G., Jr.; Qualters, J.R.; Niskar, A.S.; Sinclair, A.H.; Tolsma, D.D.; Adeniyi, K.A. Methods for characterizing fine Particulate Matter using satellite remote sensing Data and ground observations: Potential use for environmental public health surveillance. J. Air Waste Manage. Assoc. 2007, 59, 865-881.

31. Gupta, P.; Christopher, S.A. Particulate Matter air quality assessment using integrated surface, satellite, and meteorological products: Multiple regression approach. J. Geophys. Res. 2009, 114, D14205.

32. Homer, C.; Huang, C.; Yang, L.; Wylie, B.; Coan, M. Development of a 2001 National Land-Cover Database for the United States. Photogramm. Eng. Remote Sensing 2004, 70, 829-840.

33. Wickman, J. D.; Stehman, S.V.; Fry, J.A.; Smith, J.H.; Homer, C.G.. Thematic accuracy of the NLCD 2001 Land Cover for the conterminous United States. Remote Sens. Environ. 2010, 114, 1286-1296.

(C) 2011 by the authors; licensee MDPI, Basel, Switzerland. This article is an open access article distributed under the terms and conditions of the Creative Commons Attribution license (http://creativecommons.org/licenses/by/3.0/). 